\title{
TEACHING FIELD SURVEYING TO FINAL-YEAR UNIVERSITY STUDENTS: AN EXAMPLE FROM WESTERN AUSTRALIA
}

\author{
W. E. Featherstone \\ Western Australian Centre for Geodesy \& The Institute for Geoscience Research, \\ Curtin University of Technology, GPO Box U1987, Perth WA 6845, Australia
}

\author{
G. P. Galvin
}

Oracle Surveys Pty Ltd, GPO Box 668, Victoria Park WA 6979, Australia

\begin{abstract}
At Curtin University of Technology, all final-year undergraduate surveying students must take a field-to-finish survey camp as part of their degree programme. This paper outlines the six exercises now set and their educational rationale, including a novel system where a production environment is replicated by setting penalties for late submission of assignments. In addition, some deliberate 'traps' are set to reinforce routine checks of their observations. The approaches and philosophies used here may be of use/interest to other field-surveying educators.
\end{abstract}

\section{BACKGROUND}

Every September, all final-year students reading for the Bachelor of Surveying degree at Curtin University of Technology must take an 11-day field survey camp at Guilderton, Western Australia. Prior to 1994, our final-year survey camps were run on a somewhat ad hoc basis, where project-specific tasks were conducted for privatesector and government organisations. Whilst this provided financial subsidy to these various survey camps, they lacked in educational value because of the sometimeslimited nature of the tasks involved [3].

Moreover, senior undergraduate students are not necessarily experienced enough to deliver the (sometimes quite specific) outcomes expected by these organisations. This inexperience led to pressure on the supervisors to finalise some of the tasks expected by these financiers. Given these problems, it became apparent that it was necessary to significantly restructure our survey camp in order to make it an entirely in-house exercise, based on a more sound student-centred educational rationale. Importantly, this has allowed focus to be placed on the students' education (especially as they now have to pay more for it in Australia), as well as to broaden the range of surveying and project-management activities conducted.

Here we describe the now-evolved structure of survey camp as at 2007, which may be of value to surveying educators elsewhere.

\section{Educational Aims of Survey Camp}

The undergraduate unit, Applied Geodetic Surveying 482, comprises $12.5 \%$ of the fourth-year's teaching credits. This is in addition to many other field-based activities throughout the programmes offered by the Department of Spatial Sciences; see http://www.spatial.curtin.edu.au. It consolidates the students' knowledge in a production-type environment, sometimes under quite challenging conditions, thus preparing them for their careers, not necessarily only in surveying. 
The unit predominantly comprises a survey camp under as-realistic-as-possible conditions, involving teamwork and organisational skills development to complete a geodetic survey to national standards [7], and a hypothetical rural land subdivision according to Western Australian legislation [4, 5]. The field surveys include reconnaissance, triangulation, trilateration, traversing, GPS, EDM, astronomical observations, spirit levelling, closure checks, least squares network adjustment and analysis, datum transformations, and map projections. Auxiliary - yet important activities include equipment calibration, project cost estimation, logistical planning, and professional report presentation to 'clients' in a production-type environment.

One of the many policies at Curtin University of Technology requires that learning outcomes are now specified for each unit in every degree programme. While nauseating to map a unit to a set of generic attributes that a university graduate should possess, it was rewarding to see that the original aims of survey camp met and sometimes exceeded these, long before this University policy was adopted. On successful completion of the unit, the student must be able to demonstrate achievement of and base-level competence in:

- The major aspects of organising and conducting field surveys in realistic and production-type environments;

- Ability to execute geodetic and cadastral surveys according to national and State standards, specifications and laws (cf. $[4,5,6])$;

- Ability to check, analyse and adjust a variety of surveying data types collected by a variety of different field surveyors;

- Elementary experience in small-project management and the proper costing of small surveying jobs;

- Improved written and oral communication skills through the timely presentation of client-focussed reports;

- Understanding and application of Occupational Health and Safety issues [1].

\section{SuRvey CAMP Structure}

\section{The survey area and transportation}

The main focus of Applied Geodetic Surveying 482 is an 11-day survey camp, which is conducted over a $\sim 3 \mathrm{~km}$ by $\sim 4 \mathrm{~km}$ area near Guilderton, Western Australia (Figure 1). Guilderton is a small town at the mouth of the Moore River, located $\sim 100$ $\mathrm{km}$ due north of Perth. It is a holiday resort and thus offers accommodation and other amenities for the $\sim 15-30$ students who attend survey camp each year. The availability of reasonably low-cost accommodation is useful to run such a survey camp on a restricted budget.

The survey areas are situated on Crown land and the road reserve, centred $\sim 2 \mathrm{~km}$ north of the Guilderton town centre (Figure 1). The students are transported to, from and within the survey area using minibuses, which avoids the students from using their own vehicles. Previous [unfortunate] experience has shown that some students cannot be trusted with rental vehicles. However, this has sometimes proven problematic for the students because the minibuses may not always be available at the times that they want. Despite this, transport has not been a limiting factor on the students reaching the 
submission deadlines (covered later), principally because of the availability of low-cost two-way radios.

There is also the issue of crowd control, where many surveying degree programmes are dominated by - sometimes boisterous - males. As such, rules on drunkenness and unruly behaviour are strictly enforced, with the ultimatum that students who misbehave or do not follow a Code of Conduct (described later) will be returned to Perth and thus fail the unit. Thankfully, we have not yet have had to implement this ultimatum, but it is necessary to establish such rules, if only for the students' personal safety.

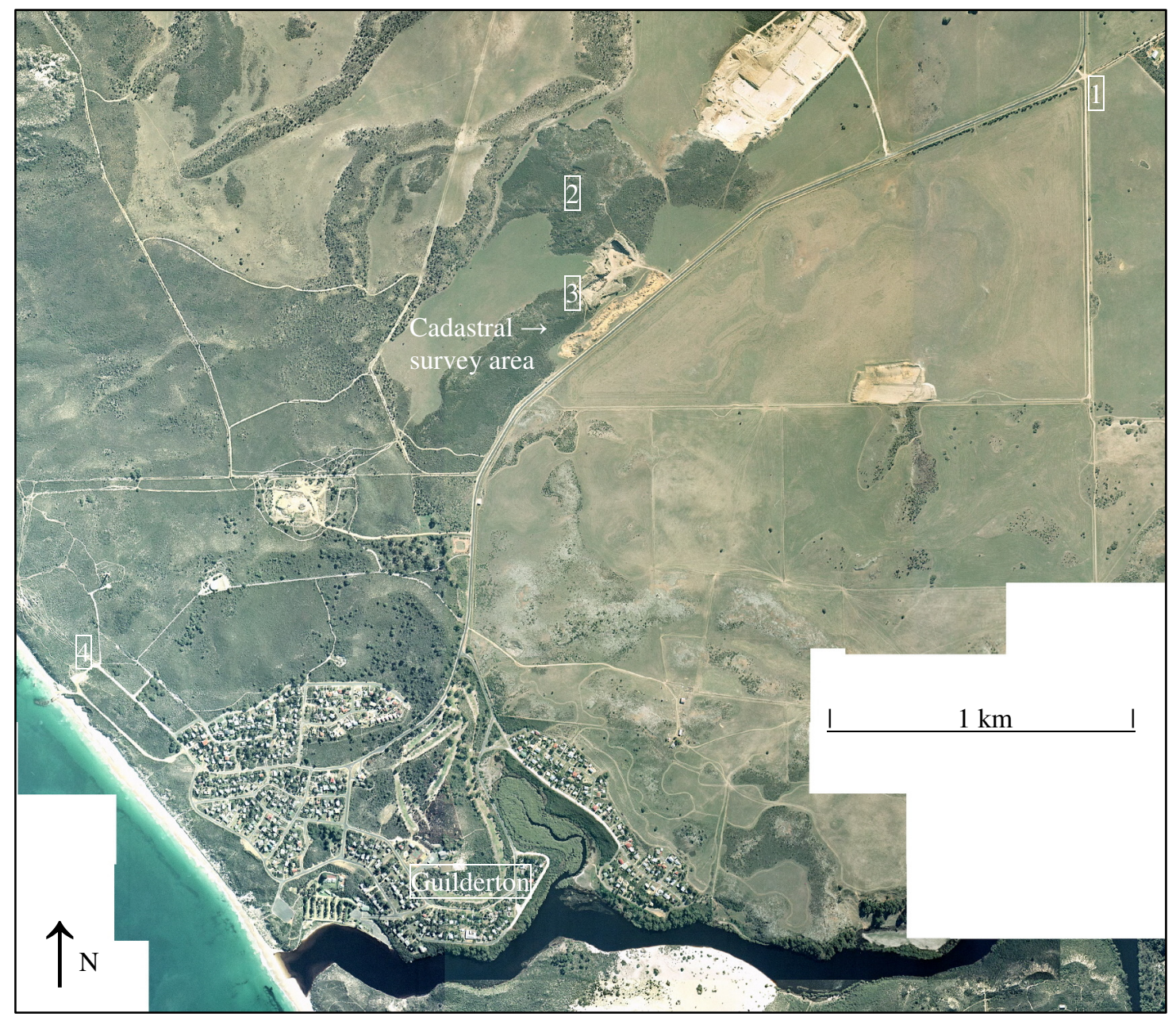

Fig. 1. A composite aerial photograph of the survey area in Guilderton, Western Australia (courtesy of James MacKensie), showing approximate locations of the four new stations to be coordinated during Tasks $\mathrm{C}$ and $\mathrm{D}$ and the cadastral survey area in Task E (cf. Table 1)

\section{The tasks set and assessment}

The students are typically divided into groups of between four and six people, and all groups undertake four separate tasks over the duration of the survey camp, as well as one task before and one task after the survey camp (Table 1). This structure allows the groups to be sufficiently small so as to allow each student to be exposed to all aspects of each task, whilst allowing for limitations imposed by the amount of surveying equipment available. Each group rotates around the tasks set (Table 1), thus allowing optimal use of the equipment and software licenses. 
Table 1. The six main tasks required for Applied Geodetic Surveying 482

\begin{tabular}{|c|c|}
\hline $\begin{array}{l}\text { Task A } \\
\text { (before } \\
\text { survey } \\
\text { camp) }\end{array}$ & $\begin{array}{l}\text { Project planning and cost estimation (group submission) } \\
\text { - Calibration, checking and testing of all surveying equipment; } \\
\text { - Installation, checking and testing of all computer software; } \\
\text { - } \quad \text { Preliminary estimation of survey costs per task. }\end{array}$ \\
\hline $\begin{array}{c}\text { Task B } \\
(0.5 \text { day })\end{array}$ & $\begin{array}{l}\text { Reconnaissance and monumentation (group submission) } \\
\text { - Location of existing geodetic control from access diagrams and } \\
\text { verification of stability with respect to witness marks; } \\
\text { - Establishment and witnessing of four temporary geodetic stations } \\
\text { for Tasks C and D (below); } \\
\text { - Preparation of GPS sky visibility plots; } \\
\text { - Preparation of access diagrams for all new geodetic stations; } \\
\text { - Updates, if necessary, to existing access diagrams; } \\
\text { - } \quad \text { Report preparation and submission by the specified firm deadline. }\end{array}$ \\
\hline $\begin{array}{c}\text { Task } \mathbf{C} \\
(5 \text { days })\end{array}$ & $\begin{array}{l}\text { Terrestrial-geodetic control survey (group submission) } \\
\text { - Daily checks of survey equipment; } \\
\text { - Determination of Geocentric Datum of Australia 1994 (GDA94), } \\
\text { Map Grid of Australia } 1994 \text { (MGA94) and Australian Height } \\
\text { Datum (AHD) coordinates of the four new stations in Figure } 1 \\
\text { using terrestrial survey techniques (directions, distances, } \\
\text { trigonometric heighting, spirit levelling) according to Australian } \\
\text { class C standards [7]; } \\
\text { - Orientation of the geodetic network with respect to a single GDA94 } \\
\text { control station near station } 2 \text { in Figure } 1 \text { using solar and stellar } \\
\text { determinations of astronomic azimuth and application of Laplace } \\
\text { corrections to give geodetic coordinates (e.g., [10]); } \\
\text { - Determination of GDA94, MGA94 and AHD coordinates of the } \\
\text { Guilderton lighthouse spire, which is located near station } 4 \text { in } \\
\text { Figure 1; } \\
\text { - Survey data analysis (including field checks), reduction to the } \\
\text { GRS80 ellipsoid, least-squares network adjustment and analysis, } \\
\text { horizontal and vertical geodetic datum transformations, and map } \\
\text { projections to the MGA94 and Lancelin Coastal Grid 1994 } \\
\text { (LCG94); } \\
\text { Assignment of class to the survey results [7]; } \\
\text { - Actual cost estimation for the survey; } \\
\text { Report preparation and submission by the specified firm deadline. }\end{array}$ \\
\hline $\begin{array}{l}\text { Task D } \\
(2.5 \\
\text { days })\end{array}$ & $\begin{array}{l}\text { GPS-geodetic control survey (group submission) } \\
\text { - Daily checks of survey equipment; } \\
\text { - } \quad \text { Determination of GDA94, MGA94 and AHD coordinates of the } \\
\text { same four control stations used in Task C (Figure 1) with respect to } \\
\text { two existing GDA94 control stations using relative carrier-phase } \\
\text { GPS techniques according to Australian class C standards [7]; } \\
\text { - Survey data analysis (including field checks), least-squares network } \\
\text { adjustment and analysis, horizontal and vertical datum }\end{array}$ \\
\hline
\end{tabular}




\begin{tabular}{|c|c|}
\hline & $\begin{array}{l}\text { transformations, and map projections to the MGA94 and LCG94; } \\
\text { - Assignment of class to the survey results [7]; } \\
\text { - Actual cost estimation for the survey; } \\
\text { - Report preparation and submission by the specified firm deadline. }\end{array}$ \\
\hline $\begin{array}{l}\text { Task E } \\
\quad(2.5 \\
\text { days })\end{array}$ & $\begin{array}{l}\text { Cadastral Survey (group submission) } \\
\text { - } \quad \text { Daily checks of survey equipment; } \\
\text { - Hypothetical subdivision of a simulated rural lot (Figure 2) using } \\
\text { parallel offset techniques, according to the relevant Acts and } \\
\text { Regulations in Western Australia }[\mathbf{4 , 5 ]} \text {; } \\
\text { - } \text { Critique of the original surveyor's techniques; } \\
\text { - } \text { Actual cost estimation for the survey; } \\
\text { Report preparation and submission by the specified firm deadline. }\end{array}$ \\
\hline $\begin{array}{l}\text { Task F } \\
\text { (after } \\
\text { survey } \\
\text { camp) }\end{array}$ & $\begin{array}{l}\text { Project summary (individual submissions) } \\
\text { - A combined least-squares adjustment of all the GPS- and } \\
\text { terrestrial-geodetic data collected by their group in Tasks C and D; } \\
\text { - Survey data analysis, horizontal and vertical datum } \\
\text { transformations, and map projections to the MGA94 and LCG94; } \\
\text { - Assignment of class to the survey results [7]; } \\
\text { - Suggested improvements for future survey camps; } \\
\text { - Individual preparation and submission by the specified firm } \\
\text { deadline. }\end{array}$ \\
\hline
\end{tabular}

The Australia-specific geodetic terminology in Table 1 needs some clarification. The Geocentric Datum of Australia 1994 (GDA94) is the horizontal geodetic datum for Australia that has been in use since 2000 [6]. The Map Grid of Australia 1994 (MGA94) is a Universal Transverse Mercator grid across Australia [6]. The Australian Height Datum (AHD) is the vertical geodetic datum for Australia [9]. The Lancelin Coastal Grid 1994 (LCG94) is a Local Transverse Mercator grid that covers the survey area, defined by a central meridian of $115^{\circ} 22^{\prime} 00^{\prime \prime} \mathrm{S}$, a central scale factor of 1.00000157, a false easting of 50,000.000 m and a false northing of 3,650,000.000 m. MGA94 and LCG94 grid coordinates come only from GDA94 latitude and longitude.

While most of the assessment for Applied Geodetic Surveying 482 is based on group assignments (Table 1), $40 \%$ of the assessment in Tasks A through $\mathrm{E}$ is based on each individual's field performance and contribution to the group effort. [Unfortunately], this is necessary because some poorer students may let the better students undertake most of the work. Albeit seemingly subjective, it is rather easy for the supervisors to determine who is making a real contribution and who is not. Moreover, having the field performance element to the assessment does not disadvantage good students that may be in a group of poorer students.

An individual report is set on the combined least-squares adjustment of the data from tasks $\mathrm{C}$ and D after the end of survey camp (Task F, Table 1), where students have an additional chance to differentiate themselves from the remainder of group. In many instances, students are able to discover and correct blunders (mainly in the 
reductions rather than the observations) when compared to the GPS for the same four survey marks in Figure 1. This also provides a cross-check on the in-field assessments by the supervisors, and rewards students who prove to really understand the entire survey camp experience.

Based on verbal feedback from students over the past 10+ years, survey camp is a very intense yet rewarding experience. It also engenders other generic skills that are not necessarily embedded in a 'chalk and talk' degree programme. For instance, students have to work meet firm deadlines (described later), while also living together. They also have to develop and apply on-the-fly problem-solving skills in order to meet the objectives set. In the repeated experience of the first-named author, our graduates later speak fondly about survey camp.

\section{Geodetic surveys}

The network geometry for Tasks $\mathrm{C}$ and $\mathrm{D}$ (Table 1) is [deliberately] poor because of a combination of access to land and station inter-visibility. The network geometry is an east-west-elongated quadrilateral (that cannot be fully braced for Task C) of $\sim 4 \mathrm{~km}$ by $\sim 0.5 \mathrm{~km}$. This forces the students to devise strategies to overcome the difficulty set (i.e., problem-solving skills), as well as ensuring that they can make observations to satisfy the class required [7]. Students also have to consider locating their stations such that another group will not obstruct them. This makes them realise the value of eccentric stations, and that the reference marks of an existing geodetic survey mark can be just as useful as the primary mark.

Tasks $\mathrm{C}$ and $\mathrm{D}$ give the students an appreciation of the relative merits of geodetic surveying using terrestrial and GPS techniques, and the differences in their respective data reduction and analyses. The four new stations in Figure 1 are coordinated using each technique, with the datum (and orientation) of the terrestrial network being defined by a single GDA94 control station near station 2 and a geodetic azimuth derived from star observations, whereas the datum and orientation of the GPS survey are defined by two GDA94 control stations and one benchmark.

A network simulation using the SIM option in Geolab (http://www.msearchcorp.com/) indicated that, given the precision of the instruments available, only Australian class C standards [7] can realistically be achieved for the terrestrial-geodetic task. This ensures that the students use all the equipment properly and introduce sufficient redundancy into their observation strategies. Australian class $\mathrm{C}$ standards must be met for all the geodetic tasks set; otherwise, the group will fail that task. This is very easy to assess from a [successful] minimally constrained leastsquares adjustment of the observations [7].

Quite often, some students are tempted to take the 'path of least resistance' by cutting corners and not applying proper field checks, but the need for this becomes immediately apparent. One egregious anecdote is that two students thought incorrectly - that they could spirit-level $\sim 10 \mathrm{~km}$ without intermediate checks. A few days later, and contrary to repeated advice from the supervisors, they eventually realised that temporary benchmarks are indeed useful. While not directly assessed, survey camp soon reinforces the utility and value of field checks. 


\section{Cadastral survey}

Thanks to the initiative of the second-named author in 2004, we introduced a cadastral element (Task E, Table 1) to the previously only geodetically focussed survey camp [3]. Here, a hypothetical parcel of rural land (Figure 2) has to be subdivided according to Western Australian legislation $[4,5]$. An actual land parcel is not used because the students are not yet licensed surveyors in Western Australia, as well as to protect the cadastre. In order to avoid students finding spikes identified by a previous group in the rotational mode that survey camp is run in, four separate cadastral boundaries have been set up. Weathering and foliage growth makes each cadastral survey area appear fresh and thus realistic each year.

One particularly challenging element in this task is the requirement to use parallel offsets along all boundaries of the existing lot. Before the start of survey camp, some students complain that this is not necessary given their perceived inter-visibility among stations so as to allow simple radiation. Ensuring that one is parallel is not so trivial, however, which teaches the students to pay careful attention to their plane trigonometry. We deliberately complicated this task by introducing the need to middle-in on one boundary, where two stations are not inter-visible. Based on verbal feedback from the students, this task is a challenge but also a success.

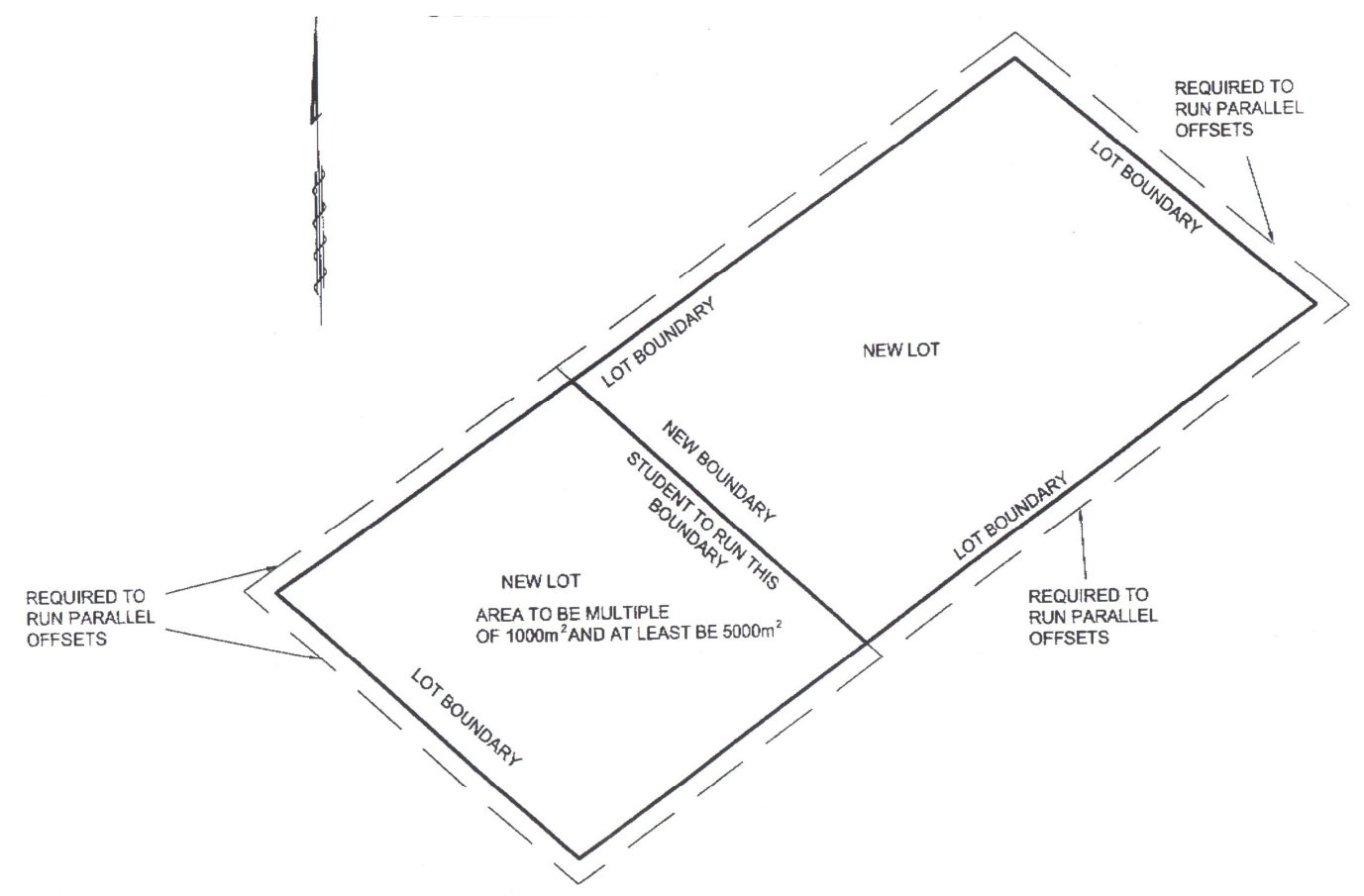

Fig. 2. A schematic of the hypothetical rural land subdivision for Task E; the survey area is approximately $200 \mathrm{~m}$ by $50 \mathrm{~m}$

\section{Simulation of a production environment}

In order to replicate a real-world production environment during survey camp, firm submission deadlines for each task are enforced routinely. Typically, students tend to underestimate the amount of time required to reduce, least-squares adjust, analyse and map project (Tasks $\mathrm{C}$ and $\mathrm{D}$, Table 1 ) their observations. The intensity caused by these firm deadlines demonstrates to the students that a geodetic or cadastral survey is never completed just because the observations have been collected. 
To simulate a production environment, reports on each task that are submitted after the specified deadlines have their marks reduced by $10 \%$ per working hour late, with working hours set between 8.00 am and $6.00 \mathrm{pm}$. For instance, if a group submits a report that was due at $6.00 \mathrm{pm}$ before 8.00 am the following day, then it only loses $10 \%$ of the marks. Especially in the first half of the survey camp, groups tend to miss these deadlines, but towards the end, they operate as 'well-oiled' machines, regularly meeting the deadlines. This alone justifies this strategy.

Over the years, verbal feedback from the students has consistently indicated that this 'regime' makes for an intense, yet rewarding, experience and teaches them to manage their efforts to deliver the necessary outcomes in a fixed time-frame. Moreover, it engenders teamwork skills that will be of use in their careers, again not only in surveying. They also learn to work with different people under sometimes-intense conditions to achieve a common goal. There have been many instances when students (and supervisors) have worked throughout the night in order to meet these deadlines.

While this strategy may appear Draconian, the rationale is that a client will expect a contractor to deliver by a specified deadline; after all, they pay for it. Lame excuses that may have worked in school, simply do not survive in the private sector, nor should they on a survey camp that attempts to replicate a production environment. Since all students will be adversely affected by the loss of marks from late submissions, they quickly learn to work together. As educators, it is particularly pleasing to observe how teams eventually gel.

In some return for these firm deadlines, the supervisors mark the field-submitted assignments during survey camp. Depending on the pressures of transport, assignments are returned with handwritten comments, verbal feedback and a provisional mark within a day or two. Based on verbal feedback, the students appreciate this quick turn-around because it allows them to better understand the requirements of the survey camp and the supervisors' marking schemes. Final marks are assigned based on these reports in the light of the complete survey, i.e., the preliminary marks are reviewed after Task F (Table 1) is submitted.

\section{EdUCATiOnAl RATiOnALE}

A number of educational objectives lie behind the above modes of delivery for survey camp. Principally, it consolidates most of the previous teaching in the BSurv programme. The variety of tasks now set on survey camp requires the knowledge gained during formally taught units to be applied in near-real-world geodetic and cadastral surveying environments. This is achieved predominantly in a self/grouplearning mode, where students in the groups and among groups can also assist one another; this is encouraged, but with care over plagiarism.

In addition, the continuous availability of at least two academic staff during the whole survey camp allows for one-on-one tuition, if needed, where each student is guided (at their own rate) through concepts that they might not have grasped fully from formally taught units. This form of tuition, though not financially viable at most universities, is widely acknowledged to deliver the best mode of education. 
One deliberate trap introduced into survey camp was designed to teach the students to be critical of existing geodetic control and not take its stated accuracy for granted. This is achieved by providing ellipsoidal heights from a mixture of AUSGeoid93 [9] and AUSGeoid98 [2] to transform AHD heights as control for the GPS surveys, and providing an old Australian Geodetic Datum 1984 (AGD84) summary sheet for one station, which requires transformation using the techniques in [6]. Most students overlook this discrepancy in the early stages, but their checks usually uncover the datum and geoid model differences in the Guilderton area.

Another trap occurs in Task $\mathrm{C}$, which had not been deliberately introduced, but provides further justification of the need for a surveyor's scepticism about existing geodetic control. The published (in 1994) AHD height of the GDA94 control point had been established from a single levelling spur and an error of $\sim 3 \mathrm{~cm}$ was uncovered by the students using closed (on their own work) spirit-levelling between this point and two existing benchmarks not on the spur. This error has since been corrected by Landgate, the Western Australian geodetic agency, but survey camp deliberately continues to use the erroneous 1994 summary sheet.

\section{ADMINISTRATIVE ISSUES}

\section{Traffic management}

All Australian States and Territories set rules for the use of the road reserve. In Western Australia, the road reserve is not only the sealed surface, but also the land either side to the fenced boundary. Therefore, even surveying to the side of the sealed road surface is governed by road laws. In order to be authorised to devise and implement a traffic management plan requires a two- or three-day course, followed by independent examination by the Main Roads Department. Also, only authorised persons may deploy traffic signage and other traffic-flow management devices. As such, survey camp supervisors must gain traffic management qualifications.

\section{Code of Conduct and safety}

Increased litigation in modern Australian society made the fist-named author realise that it was necessary to formulate a student Code of Conduct, which has now been adopted for all other field-based activities in the Department of Spatial Sciences, and is now under consideration by the University as a whole. The motivation is that if a student is injured - or worse - while on University-based field activities, the University and staff involved are protected from litigation as far as the law permits.

The Code of Conduct for survey camp is available as Electronic Supplementary Material to this paper, which is available at: http://www.cage.curtin.edu.au/ will/ESMSR2008.pdf. This Code sets rules for students' behaviour (in addition to rules set in the survey camp teaching materials) and makes them appreciate Occupational Health and Safety issues [1]. It covers general conduct and general health and safety expected of any field surveyor, as well as Australia-specific issues such as protection from the sun and poisonous animals, road regulations and Aboriginal heritage. 
The Code also includes a request for medical details (students are not obliged to provide this for reasons of personal privacy) in the event of an emergency. This will allow supervisors to advise medics in the event of an emergency. Guilderton is not serviced by a medical centre (the nearest is $\sim 50 \mathrm{~km}$ away), so is covered by the Royal Flying Doctor Service. Thankfully, no serious such emergency has yet occurred. However, it is essential for supervisors to have emergency management plans in place (i.e., duty of care).

\section{CONCLUDING REMARKS}

This short paper has given an overview of the structure and educational rationale of the field-based unit, Applied Geodetic Surveying 482, which is taken by all final-year undergraduate students in the surveying degree programme offered by the Department of Spatial Sciences at Curtin University of Technology. This unit aims to consolidate previous formally taught units through the application of this knowledge to a series of formally structured field-surveying tasks.

In addition to an education in field-surveying, survey camp develops other skills that are expected of the modern graduate. These include project- and time-management, interpersonal skills, communication skills, and the ability to work as a team towards a common goal within a specified time-frame.

Finally, from the perspective of educators, the course is rewarding because the benefits to the students are seen directly in 'real-time' and the verbal feedback from the students on completion of survey camp has always been positive.

Postscript: Surveying educators who wish to view the full suite of teaching materials used for Applied Geodetic Surveying 482 should contact the first-named author at W.Featherstone@curtin.edu.au. The Code of Conduct is available as Electronic Supplementary Material from http://www.cage.curtin.edu.au/ will/ESM-SR2008.pdf.

\section{ACKNOWLEDGEMENTS}

We wish to thank Landgate, formerly the Western Australian Department of Land Information, for providing geodetic control summary sheets for the survey area, and the Shire of Gingin for allowing access to the facilities of Guilderton Caravan Park and to the survey area. We would also like to thank previous supervisors who have contributed to and helped to run survey camp, who are Dr M.L. Roderick (now at Research School of Biological Sciences, The Australian National University), N.R. Douglas (now at Mt Keith Nickel Operation, BHP Billiton), S.W. Munsie (ret.), Dr S.J. Claessens, Dr M.P. Stewart (ret.), L.R. Atkinson and Dr M. Kuhn (all at Curtin University of Technology). This is The Institute for Geoscience Research publication number 109.

\section{References}

1. Consulting Surveyors of Western Australia, 2001. Survey Safe: Managing the Risks, Consulting Surveyors of Western Australia, Perth.

2. Featherstone, W.E., Kirby, J.F., Kearsley, A.H.W., Gilliland, J.R., Johnston, G.M., Steed, J., Forsberg, R. and Sideris, M.G., 2001. The AUSGeoid98 geoid model of Australia: 
data treatment, computations and comparisons with GPS-levelling data. Journal of Geodesy, 75 (5-6): 313-330, doi: 10.1007/s001900100177.

3. Featherstone, W.E., Roderick, M.L. and Munsie, S.W., 1999. Teaching geodetic field surveying to final-year students at Curtin University of Technology, proceedings of the 40th Australian Surveyors Congress, Fremantle, Australia, November, pp 376-381.

4. Government of WA, 1909. Licensed Surveyors Act 1909, State Law Publisher, Perth, Australia, 41 pages, http://www.austlii.edu.au/au/legis/wa/consol_act/lsa1909237/

5. Government of WA, 1961. Licensed Surveyors (Guidance of Surveyors) Regulations 1961, State Law Publisher, Perth, Australia, 23 pages, http://www.austlii.edu.au/au/legis/wa/consol_reg/lsosr1961574/

6. Inter-governmental Committee on Surveying and Mapping, 2002. GDA Technical Manual (version 2.2), Inter-governmental Committee on Surveying and Mapping, Canberra, Australia, 63 pages, http://www.icsm.gov.au/icsm/gda/gdatm/index.html

7. Inter-governmental Committee on Surveying and Mapping, 2004. Standards and Practices for Control Surveys (version 1.6), Inter-governmental Committee on Surveying and Mapping, Canberra, Australia, 90 pages, http://www.icsm.gov.au/icsm/publications/sp1/sp1v1-6.pdf

8. Roelse A., Granger, H.W. and Graham, J.W., 1975. The adjustment of the Australian levelling survey 1970 - 1971, second edition, Technical Report 12, Division of National Mapping, Canberra, Australia, 80 pages.

9. Steed J. and Holtznagel, S., 1994. AHD heights from GPS using AUSGeoid93, The Australian Surveyor, 39 (1): 21-27.

10. Torge, W., 2001. Geodesy, third edition, Walter de Gruyter, Berlin, Germany. 